\title{
PREFACE: CENTER FOR MEDITERRANEAN ARCHAEOLOGY AND THE ENVIRONMENT - SPECIAL JOINT ISSUE OF RADIOCARBON AND TREE-RING RESEARCH
}

\author{
CHARLOTTE L. PEARSON ${ }^{1,2}$ and STEVEN L. KUHN ${ }^{2}$
}

${ }^{1}$ CMATE, Laboratory of Tree-Ring Research, University of Arizona.

${ }^{2}$ CMATE, School of Anthropology, University of Arizona.

The Center for Mediterranean Archaeology and the Environment (CMATE) is a new interdisciplinary research group based at the University of Arizona with institutional partners throughout the Mediterranean region. The establishment of CMATE builds on a legacy of over 75 years of cross-disciplinary collaboration between the world's founding Laboratory of Tree-Ring Research and colleagues in archaeology, geosciences, and other units. This combination has already revolutionized what we know about Southwestern (U.S.) archaeology by providing an absolutely dated chronological framework to underpin studies of human and environmental interactions across the region in the last 2 millennia. It has also played a central role in the development and improvement of the radiocarbon dating method for a global user community. With our new focus on questions of chronology and human/environmental interactions in the Mediterranean region, combining fields of expertise not to be found within the confines of a single university department or even a college, we aim to provide new approaches to refining chronologies and expanding interpretations, synthesizing multiple lines of proxy evidence with integrated archaeological, anthropological, geological, climatological, and other analyses. By integrating diverse skill sets with the knowledge and expertise of a range of Mediterranean-based partners we aim to make the Mediterranean Basin the premier "observatory" for studying societal responses to climate change, while also helping illuminate some of the key turning points of human history in the cradle of old world civilizations. This collection of papers, published as a joint issue of Radiocarbon and Tree-Ring Research to underline the core interdisciplinary potential of our collective, evidenced since CMATE was established in 2013. The papers represent part of the diverse range of research projects already undertaken by CMATE partners and illustrate part of its future potential.

We begin with the paper by Malcolm H. Wiener, presented at our inaugural meeting, which expounds a broad synthesis of the interactions of climate change and agency in the collapse of civilizations throughout the ancient Near East and Mediterranean during the Bronze Age, in particular referencing the work of Weiss and others on events between approximately 2300 and 2000 BC. Wiener has been a leading proponent for the integration of science and archaeology in the Mediterranean region for many years, and in synthesizing a vast sweep of archaeological evidence he presents one detailed example of a time period that could benefit greatly from the types of improved, high-resolution chronological frameworks the CMATE group aims to develop.

Quade et al.'s work on carbon-14 and the isotopic composition of hackberry endocarps from the Neolithic site of Aşıklı Höyük in central Turkey represents an important advance towards improved dates for Neolithic (and other period) sites in the Near East where charcoal is not always preserved for radiocarbon dating. Hackberries were consumed in large quantities at many Neolithic sites, and this study demonstrates that the calcareous endocarp surrounding their seed can be successfully radiocarbon dated. Moreover, carbon and oxygen isotopic systematics are shown to be indicative of potential source areas for harvesting, providing an insight into early human/environmental interactions regarding this food resource.

Kondopoulou et al.'s multidisciplinary archaeometric approach to studying Hellenistic and Early Roman kilns in Greece represents the increasing use and improvement of archaeomagnetism as an alternate dating technique in the Mediterranean region. As localized secular variation curves continue to be developed and databases constructed and maintained, this technique offers an increasing value for archaeological chronology, especially when combined in a multiproxy approach.

Although interdisciplinary radiocarbon innovations and fresh archaeometric approaches provide two important means to improve chronological resolution in our region, we anticipate that our group will make a third, very substantial contribution to old world chronology through focused effort on the development and extension of tree-ring data networks in the region. CMATE includes a large number of dendrochronologists who have been leading various aspects of tree-ring research in the Mediterranean region for many decades. From Peter Kuniholm's decades of data collection and work on the Aegean and Near Eastern dendroarchaeology, to Tomasz Ważny's work across the Balkans, to Ramzi Touchan's extensive network of chronologies and climate reconstructions in North Africa and the Eastern Mediterranean and Valerie Trouet's work on atmospheric circulation patterns, these researchers and their collaborators are well placed to make many major new advances in tree-ring chronology and climate reconstruction for the wider Mediterranean region in coming years. 
In this special issue, Ważny et al. present an extension of treering data from forest, historical, and archaeological sites along a north-south transect between Poland and northwestern Turkey. The connections they demonstrate bridge between existing networks of long regional oak tree-ring chronologies in NorthCentral Europe and the extensive but noncontinuous records from the East Mediterranean. This finding has significant implications for linking up floating chronologies across wider regions. Prospects for extending such oak networks into deeper time are demonstrated by Pearson et al., who present preliminary dendrochronological and radiocarbon findings indicating potential for a new multimillennia subfossil oak chronology for the Balkan region.

Touchan et al. provide a comprehensive review of the current state of dendroclimatic research across the East Mediterranean and North Africa and highlight the value of this research for contemporary planning as well as understanding past societies. Touchan and colleagues have developed extensive systematic networks of tree ring-width chronologies from climaticallysensitive ancient living and dead trees extending back to the 1st millennium $\mathrm{AD}$, and used them to produce the first highly sensitive histories of drought in North Africa. Extension of these chronologies using archaeological materials opens up major new possibilities for studies of human and environmental interaction in this region during key time periods.

Trouet's paper presents a new dendroclimatological study, a late summer temperature reconstruction (AD 1675-1980) for the northeastern Mediterranean based on maximum latewood density tree-ring data at high-elevation sites. These data contribute to an improved understanding of regional vs. global-scale drivers of past climate variability, in particular, in this case, the role of the summer North Atlantic Oscillation. Understanding the global circulation patterns that lead or link to climatic change in Mediterranean regions is essential in terms of future predictions, but also in evaluating the impact of known past global-scale climatic anomalies (for example, the $2200 \mathrm{BC}$ event referenced by Wiener).

The paper by Brewer raises the critical issue of improved facility for data management in dendroarchaeology as part of a larger community-wide move towards a "global standard" for dendro- chronological data. It is hoped that tools such as the Tellervo software described will serve the tree-ring research community by making collection and storage of data, and accompanying complex metadata, easier and more transparent, enabling improved data sharing and meeting funding agency requirements.

Finally, our two papers by Creasman and Kuniholm highlight prospects, problems and potential for dendroarchaeological work in Egypt, hopefully signaling a move towards new tree-ring studies in this archaeologically rich region. The history and future plans laid out present potential for a massive contribution to old world chronology in terms of resolving/confirming and linking existing chronological sequences and understanding issues of radiocarbon offset.

The Mediterranean Basin has been the locus of many worldaltering cultural developments, from the first dispersal of hominins from Africa, to early experiments with plant and animal domestication, to emergence (and decline) of some of the world's first civilizations and regional-scale networks of economic interaction. These profound developments in the human realm have unfolded in the context of a complex mosaic of environmental changes, some correlated with global climate events and others more local in nature. The Mediterranean also boasts a uniquely long legacy of systematic studies of human cultures and natural systems, reaching back into the 18th century. These features make it the perfect natural laboratory from which to gain insight into past human/environmental interactions from a deep time perspective. CMATE's aim is to utilize this natural laboratory in new and innovative ways, drawing on our collective strengths in chronology, archaeology and paleoenvironmental reconstruction.

\section{ACKNOWLEDGMENTS}

In compiling this group of papers, the guest editors wish to thank Mark McClure, Steve Leavitt, and Tim Jull for their flexibility and creative solutions for making this special joint issue of Radiocarbon and Tree-Ring Research possible. We also wish to thank 22 anonymous reviewers whose contributions significantly improved the quality of the submissions. Finally, we sincerely thank the University of Arizona Libraries' Open Access Publishing Fund for sponsoring public access to this volume. 